\title{
The Catalyst Selectivity Index (CSI): A Framework and Metric to Assess the Impact of Catalyst Efficiency Enhancements upon Energy and $\mathrm{CO}_{2}$ Footprints
}

\author{
Tiancun Xiao $^{1} \cdot$ Tara Shirvani $^{2,4}$ - Oliver Inderwildi ${ }^{2,5} \cdot$ Sergio Gonzalez-Cortes $^{1}$ • \\ Hamid AlMegren ${ }^{3}$ David King ${ }^{2} \cdot$ Peter P. Edwards ${ }^{1}$
}

Published online: 2 July 2015

(c) The Author(s) 2015. This article is published with open access at Springerlink.com

\begin{abstract}
Heterogeneous catalysts are not only a venerable part of our chemical and industrial heritage, but they also occupy a pivotal, central role in the advancement of modern chemistry, chemical processes and chemical technologies. The broad field of catalysis has also emerged as a critical, enabling science and technology in the modern development of "Green Chemistry", with the avowed aim of achieving green and sustainable processes. Thus a widely utilized metric, the environmental $\mathrm{E}$ factor-characterizing the waste-to-product ratio for a chemical industrial processpermits one to assess the potential deleterious environmental impact of an entire chemical process in terms of excessive solvent usage. As the many (and entirely reasonable) societal pressures grow, requiring chemists and chemical engineers not only to develop manufacturing processes using new sources of energy, but also to decrease the energy/carbon
\end{abstract}

Electronic supplementary material The online version of this article (doi:10.1007/s11244-015-0401-1) contains supplementary material, which is available to authorized users.

Peter P. Edwards

peter.edwards@chem.ox.ac.uk

1 King Abdulaziz City of Science and Technology-Oxford Petrochemical Research Centre (KOPRC), Inorganic Chemistry Laboratory, University of Oxford, South Parks Road, Oxford OX1 3QR, UK

2 Smith School of Enterprise and the Environment, University of Oxford, South Parks Road, Oxford OX1 3QY, UK

3 Material Research Institute, King Abdulaziz City for Science and Technology, PO Box 6086, Riyadh 11442, Kingdom of Saudi Arabia

4 Present Address: Energy and Transport Unit of the World Bank Group, 1818 H St. NW, Washington, DC 20433, USA

5 Present Address: World Economic Forum, 91-93 route de la Capite, Cologny, 1223 Geneva, Switzerland footprint of existing chemical processes, these issues become ever more pressing. On that road to a green and more sustainable future for chemistry and energy, we note that, as far as we are aware, little effort has been directed towards a direct evaluation of the quantitative impacts that advances or improvements in a catalyst's performance or efficiency would have on the overall energy or carbon $\left(\mathrm{CO}_{2}\right)$ footprint balance and corresponding greenhouse gas $(\mathrm{GHG})$ emissions of chemical processes and manufacturing technologies. Therefore, this present research was motivated by the premise that the sustainability impact of advances in catalysis science and technology, especially heterogeneous catalysis - the core of large-scale manufacturing processes-must move from a qualitative to a more quantitative form of assessment. This, then, is the exciting challenge of developing a new paradigm for catalysis science which embodies - in a truly quantitative form-its impact on sustainability in chemical, industrial processes. Towards that goal, we present here the concept, definition, design and development of what we term the Catalyst Sensitivity Index (CSI) to provide a measurable index as to how efficiency or performance enhancements of a heterogeneous catalyst will directly impact upon the fossil energy consumption and GHG emissions balance across several prototypical fuel production and conversion technologies, e.g. hydrocarbon fuels synthesized using algae-tobiodiesel, algae-to-jet biofuel, coal-to-liquid and gas-to-liquid processes, together with fuel upgrading processes using fluidized catalytic cracking of heavy oil, hydrocracking of heavy oil and also the production of hydrogen from steam methane reforming. Traditionally, the performance of a catalyst is defined by a combination of its activity or efficiency (its turnover frequency), its selectivity and stability (its turnover number), all of which are direct manifestations of the intrinsic physicochemical properties of the heterogeneous catalyst itself under specific working conditions. We will, of 
course, retain these definitions of the catalytic process, but now attempt to place discussions about a catalyst's performance onto a new foundation by investigating the effect of improvements in the catalyst's efficiency or performance on the resulting total energy and total $\mathrm{CO}_{2}$ footprint for these prototypical fuel production and fuel conversion processes. The CSI should help the academic and industrial chemical communities, not only to highlight the current 'best practice catalysts', but also draw specific conclusions as to what energy and $\mathrm{CO}_{2}$ emissions saving one could anticipate with higher efficiency/higher performance from heterogeneous catalysts in a particular fuel synthesis or conversion process or technology. Our aim is to place discussions about advances in the science and technology of catalysis onto a firm foundation in the context of GHG emissions. We believe that thinking about (and attempting to quantify) total energy and $\mathrm{CO}_{2}$ emissions reductions associated with advances in catalysis science from a complete energy life cycle analysis perspective is extremely important. The CSI will help identify processes where the most critical advances in catalyst efficiency are needed in terms of their potential impact in the transition to a more sustainable future for fuel production and conversion technologies.

Keywords Catalyst - Selectivity - Index · Fischer Tropsch synthesis · Fluidized catalytic cracking · Hydrocracking · Steam methane reforming

\section{Introduction}

Catalyst science and technology remains pivotal to the overwhelming majority of chemical manufacturing processes [1-3]. As just one example, catalyst technologies impact upon almost every aspect of the chemical and petroleum refining and petrochemical industries for fuel generation and conversion; for these industries, the economic impact of catalysis is currently estimated to be over 10 trillion dollars per year [4-6]. Moreover, catalyst technologies are increasingly integrated into many of the leading pollution control and environmental clean-up processes, including the reduction of harmful automobile emissions by catalytic converters, and nitrogen oxide emissions from combustion and Volatile OC controls [7, 8]. Importantly, therefore, catalysis takes on the role of assisting humankind in environmental sustainable development [9, 10].

Because of this continued, substantial impact throughout the global economy and critical issues of environmental sustainability, catalysis remains at the forefront of modern multidisciplinary research and development in chemistry [10-16]. New and improved catalytic materials and processes are continually being developed to achieve more rapid catalytic reaction rates (increased Turnover Frequencies) using milder, less energy-intensive reaction conditions, and enhanced selectivity to produce the desired, targeted reaction products with minimal product waste. With the advent of Green Chemistry and green, sustainable processes in the chemical and energy industries, catalysis has been listed as one of the main guiding principles for future chemistry directions [13-16]. To begin to quantify the environmental impact of any chemical process, Green Chemistry metrics have been advanced to assess the environmental impact of the manufacture of chemicals in terms of solvent waste and chemical efficiency protocols [7, 13, 17].

In the 1990's the important concept of the Environmental E Factor was advanced and developed by Sheldon to assess the environmental impact, and indeed acceptability of chemical manufacturing processes. The E Factor is defined as the mass ratio of waste-to-desired-products; specifically, it represents the sum of all raw materials input $(\mathrm{kg})$, minus the desired product, then divided by the amount of the final product $(\mathrm{kg})$ [14, 17-24].

A high $\mathrm{E}$ Factor reflects a chemical production or manufacturing process characterized by large amounts of waste and, with that, a larger, more damaging environmental impact; obviously, an ideal E Factor would be close to zero. The evolution of Green Chemistry into industrialscale processes, particularly in the pharmaceutical industry, is therefore strongly based on the E Factor concept. It attempts to target any new process or modifications to an existing process, which reduces waste, together with the potential utilization of hazardous and toxic solvents or reagents, although in the majority of cases catalysts are required to attain the ultimate goal of Green Chemistry.

Catalysis is also a leading technology to achieve the objective of energy efficiency and the reduction of Green House Gas (GHG) emissions. This is especially true in the application of heterogeneous catalysts, as they are a separable, and therefore a potentially recyclable, entity. In light of the necessary-and urgent-development and fostering of Green Chemistry practices in any transition to a sustainable energy future, we first pose-and then attempt to answer-the question "What quantitative impacts would advances in catalysis in a particular process-notably advances in a catalyst efficiency (taken as a key indicator of catalyst performance)-have on the complete "Well-toTank" total energy balance and resulting GHG emissions of important chemical fuel synthesis and fuel conversion pathways?"

We target specifically heterogeneous catalysts and their role in a variety of chemical fuel production and conversion processes and technologies. Conventionally, heterogeneous catalyst efficiency (CE) and performance is defined by the catalyst's activity, selectivity and stability, 
which is, of course, dictated by the intrinsic physicochemical nature of the catalyst itself. Here we attempt to set out, and understand, the correlation of an enhancement in $\mathrm{CE}$ with the corresponding gains one would expect in energy consumption and associated $\mathrm{CO}_{2}$ emissions for particular chemical fuel synthesis and fuel conversion processes.

We focus here on this important issue in relation to heterogeneous catalysts, where the active catalysts are typically used in a fixed bed configuration, a slurry or a fluidized reactors $[16,25,26]$. Through the quantitative and also semi-quantitative analysis of several important prototypical catalyst-dependent fuel production and conversion processes, we outline the critical importance of catalysis science not only for the development of a low-carbon fuel mix, but also to highlight the potential impact of any $\mathrm{CE}$ improvement on energy consumption-typically fossil energy fuel consumption-and associated GHG emissions.

For a variety of manufacturing processes relating to fuel production and conversion we have therefore employed a complete life cycle analysis (LCA) methodology to study a catalysts performance in combination with the resulting total energy consumption and corresponding total $\mathrm{CO}_{2}$ emissions for the complete "Well-to-Tank" (WTT) processes. We find that the improvement of catalyst performance, here taken as the improvement in CE, will exert a particularly significant effect on any processes, or contributing processes, involving Fischer Tropsch synthesis, (e.g. for Gas-To-Liquid (GTL) and Coal-To-Liquid (CTL)), while any corresponding improvement in, for example, the processes of Algae-to-Biodiesel and Algaeto-Jet Biofuel is considerably less sensitive to any enhancement in CE. Importantly, in those latter cases, we find the source, nature and magnitude of the (external) fossil fuel energy input in the various processing steps dominates all contributing factors in the overall fuel production and conversion process.

We believe that a Catalyst Sensitivity Index (CSI) will assist in highlighting and evaluating what efficiency gains or energy and $\mathrm{CO}_{2}$ emission reductions one could expect with higher efficiency catalysts, set across modern, prototypical fuel conversion technologies. This approach will help to identify catalytic processes where the energy/ $\mathrm{CO}_{2}$ emissions improvement gain would be the greatest from higher efficiency in operating catalysts. We believe that the CSI approach gives yet more weight to the view that catalysis science-most importantly, in alliance with other fields, especially in the social sciences-is emerging as one of the most important of the chemical sciences in relation to its potential to impact on society, particularly in confronting the considerable scientific, technical, socio-economic and ethical challenges of the necessary transition to a sustainable or renewable energy future $[1,2,10,16]$.

\section{Methodology}

\subsection{LifeCycle Analysis (LCA)}

The LCA method in this paper is based on a methodological framework which estimates and assesses the environmental impacts attributable to the lifecycle of a product, process or an activity through identifying, and then quantifying energy and materials used and $\mathrm{CO}_{2}$ released into the environment, as well as the residue over the catalyst (in the case of our biofuel analysis). The methodology is based on the guidelines of the International Organization for Standardization (ISO) [8, 27-32] and is undertaken via the following sequential stages, each of which is described in more detail in the subsequent sections of this paper:

\subsubsection{Boundary Definition}

LCA methodology includes a full description of the product system in terms of system boundaries and functional unit used. The functional unit is defined by providing a clear description of the product or service under assessment, from which results can be interpreted and compared. The product system is determined by defining a set of unit operations which make up the product or service, and identifying the sources and destinations of all the materials and energy inputs used.

\subsubsection{Lifecycle Inventory (LCI)}

The LCI encapsulates a material and energy balance for estimating the consumption of resources and the quantities of waste flows and emissions caused by or otherwise attributable to a product's life cycle [8, 27, 33, 34]. The quantities of different resources required and corresponding emissions released are calculated per functional unit. This stage involves substantial data collection and analysis mainly on the overall mass and energy balance.

\subsubsection{Catalyst Sensitivity Impact Assessment (CSIA)}

The result of the CSIA is an evaluation of an emission reduction change with the relative catalyst performance or efficiency improvement such as activity, selectivity and lifetime durability, including the waste reduction, energy input cut, and more desirable product yields. It can also include catalyst product life cycle on a functional basis and in terms of several impact categories such as climate change, fossil energy use, land use, water use or stratospheric ozone depletion [31]. 


\subsection{Goal and Scope Definition}

As the use of various carbon containing feedstocks like biomass, coal, natural gas for fuel production will be investigated, the functional unit varies with each scenario analyzed. As an LCA provides a systematic approach to impact analysis of a product, ideally all phases of the product's lifecycle, from extraction and processing of raw materials, conversion, transportation to consumption and waste disposal should be included. A complete LCA should also evaluate the use, re-use, maintenance, recycling and final disposal. The definition of system boundaries will largely determine the outcome of an LCA [34].

In particular, an accurate assessment of future fuel systems requires a complete vehicle fuel-cycle analysis, commonly called a "Well-to-Wheel" (WTW) chain analysis. However, here our analysis is mainly based on the WTT chain analysis as we do not explicitly consider the performance of the various (end-use) engine technologies. The WTT pathway therefore consists of an analysis of the constituent feedstock preparation, transportation, conversion, upgrading and fuel distribution (Fig. 1).

\subsection{Lifecycle Inventory Analysis}

To perform quantitative mass and energy balances over each system, where applicable, global LCI databases and software, such as GREET, EcoInvent and Gabi 4, were used to provide data detailing the emissions and burdens associated with the production of raw materials and resources required for the respective fuel/feed production pathway. The mass and energy balances and all other environmental exchanges at relevant stages of the product's lifecycle have been compiled and tabulated to reflect the resource usage and associated emissions with the production of one functional unit (e.g. energy consumption reduction per unit production or normalized life cycle reduction).

\subsection{Lifecycle Impact Assessment and Interpretation}

The life cycle impact assessment stage consists of classification, characterization and normalization of all constituent steps. Classification assigns the input and output data of the lifecycle inventory to different impact categories. While input and output values can be assigned to several impact categories, a specific characterization factor is assigned in order to calculate the total potential environmental burden of each impact category. The characterization factors are made available in the literature, in the form of LCA databases and support tools. As an example, $\mathrm{CO}_{2}$ emissions would be assigned to the global warming impact category. The relative contributions of various gases to climate change are then compared in terms of carbon dioxide equivalents using global warming potentials (GWPs) as the defining characterization factor, see Table 1.

In addition to better understand the relative scale of results from certain impact categories, figures can be further normalized against a reference value, such as total resource use or emissions for a given area.

\subsection{Co-product Allocation Methods}

Our LCA methodology is further used to calculate any resulting energy credits and the level of GHG emissions avoidance through the targeted utilization of co-products. The purpose of co-product allocation is to determine how a particular environmental burden, e.g. GWP should be shared (and potentially alleviated) amongst the main product and the by-products. For example, the production of Biodiesel from microalgae generates co-products, such as crop residue (biomass cake) and glycerol. For the production of biojet fuel, a propane fuel-mix, not glycerol, is considered a by-product.

Here a so-called displacement method [35] has been employed as the main allocation method. A co-product replaces a pre-existing input product and is utilized with a corresponding co-product credit. The credit is further reflected throughout the complete lifecycle GHG emissions and energy balance, as well as the production of the
Table 1 Global warming potentials over a lifetime of 100 years

\begin{tabular}{ll}
\hline $\mathrm{CO}_{2}$ & 1 \\
$\mathrm{CH}_{4}$ & 23 \\
$\mathrm{~N}_{2} \mathrm{O}$ & 296 \\
\hline
\end{tabular}

Fig. 1 Well-to-tank (WTT) analysis: chain inputs and corresponding GHG emissions. $(E=$ fossil energy, $€=$ Money $)$ [36]

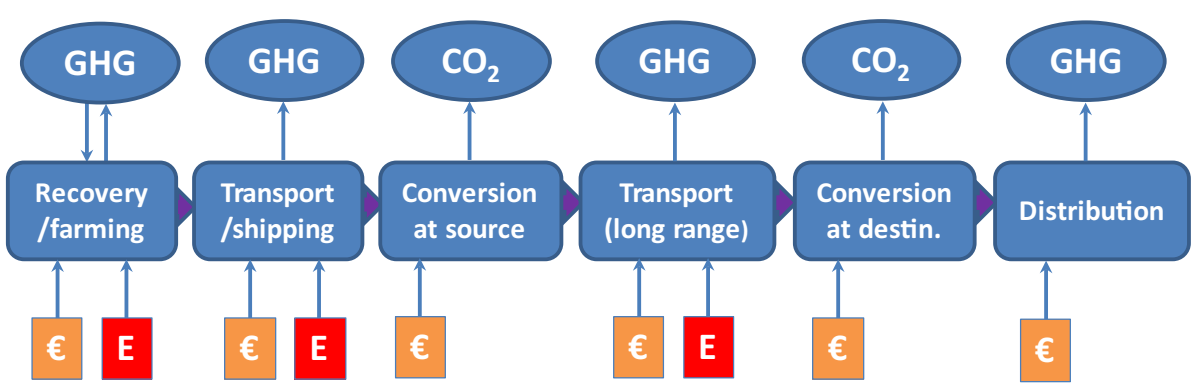

$E=$ fossil energy; $€=$ Money 
displaced input factor. Co-product credits are further subtracted from the overall LCA energy balance and carbon footprint, in order to complete the analysis. When applicable, simpler allocation methods, by economic value, calorific value or mass, have been considered.

\subsection{Dealing with Uncertainty in Lifecycle Analysis}

The reliability of LCA is affected by the dependence on input parameters from various countries, unit operations and sources as well as datasets, which are not always collected for LCA purposes per se [27, 34]. Thus far, detailed uncertainty analyses have rarely been performed as part of LCA studies, partly due to the lack of consensus about standardized methodology, varying levels of uncertainty and practical guidance provided by handbooks such as the ISO standard. However, sensitivity and uncertainty analysis are an important part of LCA studies and can provide a better understanding of accounting models, their respective results and margins of error. Their application is highly valuable for increasing the overall credibility, reliability and robustness of LCA studies.

Sensitivity is defined as the influence one independent variable has on the value of another dependent variable, both of which can either be continuous or discrete. Sensitivity analyses are common systematic procedures for estimating the impacts on the results of a study by the chosen methods and datasets. It is most often applied with either arbitrarily selected ranges of variation, or variations that represent known ranges of uncertainty. It is generally recommended that the need exists to assess the influence on variations in LCA assumptions, methods and data by conducting sensitivity analysis for what are regarded as the most significant issues. One-way sensitivity analyses are commonly practiced, as part of LCA studies with larger datasets, to assess the amount an individual input parameter value has to change, with all other parameters held constant, in order to vary the output parameter by a certain percentage [27, 34]. Other common variations of standard sensitivity analyses include tornado diagrams, scenario analysis, factorial design and multivariate analysis (MVA), critical error factor (CEF) and ratio sensitivity analysis. Among the main weaknesses of any sensitivity analysis remains the likelihood of overlooking potential synergies, the considerable effort involved in testing the robustness of each individual input parameter, and the lack of consideration for relative probability.

Uncertainty analyses for LCA studies are defined as a systematic procedure to ascertain and quantify the uncertainty introduced into the results of a life cycle inventory analysis, due to the cumulative effects of both input uncertainty and data variability. Uncertainty in input data is typically expressed mathematically as a distribution over a certain range, which should preferably be derived by statistical analysis of multiple measurements. This is in direct contrast to generic LCA studies where single point estimates are used as input parameters. It is widely accepted [31] that the application of uncertainty analysis to LCA studies remains uncommon and a practice still in its infancy. However, wherever possible the use of this type of analysis is highly advisable in order to better explain and support the resulting LCA outcomes. Uncertainty analysis is either undertaken by estimating the uncertainty of each parameter, as a function of uncertainty distribution, or by disseminating the uncertainty through models to the final output [36].

In the context of LCA-related uncertainty analyses, probabilistic simulation is often mentioned as a successful tool. It is applicable to any type of uncertainty distribution and operation and can be used in combination with different distributions, as part of the same simulation. Among the most common stochastic simulation techniques described are Monte Carlo and Hypercube simulations [36]. Monte Carlo simulation determines the probability distribution for independent model inputs by taking random samples from each input probability distribution, computing random samples into the model to obtain outputs and then repeating the previous steps $\mathrm{N}$-times to generated $\mathrm{N}$-samples of each output. As a result, Monte Carlo simulation produces a frequency distribution of each output factor, which estimates the probability distribution, which then can be analyzed with further standard statistical techniques. The larger the sample input size, the better the accuracy and resemblance to the actual probability distribution [36]. The Latin Hypercube analysis is comparable to Monte Carlo simulations, but will further divide the uncertainty distribution of an input parameter into non-overlapping intervals of equal probability. As values are chosen from each segment based on the probability within the segment, this uncertainty analysis will provide more accurate random samples.

The illustration of LCA results, as mere point estimates without uncertainty distributions, can lead to undoubted over-estimation of model accuracy and model robustness. However, presenting incomplete methods as part of the uncertainty analysis may lead to false credibility and inaccurate decision making. Therefore, it is important to find a balanced, consistent approach between offering robust and sufficient uncertainty and sensitivity analysis that will increase confidence in the derived LCA results, while not exceeding the complexity of model results and outcomes. The robustness and reliability of the LCA studies have been tested here through the application of one-way sensitivity analysis.

The complete breakdown and listing of all contributing energy expanded (utilized) and $\mathrm{CO}_{2}$ emissions, etc., for all the various processes studied by LCA is contained in the accompanying Supplementary Information. 


\section{The Catalyst Sensitivity Index (CSI): Definition and Relation with Catalyst Efficiency and Performance}

A Sensitivity Index is a number calculated by a defined procedure which provides information about the relative sensitivity of an analysis, or model, to changes in different input parameters. The CSI as set out here is a simple metric; one increases the effectiveness of a particular catalyst in a chemical manufacturing process in terms of its performance or efficiency, and then observes the subsequent impact on total energy consumption and resulting Green House Gas emissions for that entire process. Specifically, here we will explore, through a complete LCA, the impact of increases in a catalyst's efficiencyover the current "Best efficiency/ performance catalyst" as a benchmark-on the total fossil energy consumption of four selected fuel production and conversion technologies, together with the subsequent final energy $\mathrm{CO}_{2} /$ footprint of the resulting fuel product. The CSI factor, therefore, is broadly defined as the index that measures the sensitivity of the fossil fuel energy consumption and $\mathrm{CO}_{2}$ emission footprint of any of these fuel synthesis and conversion processes to increases in the respective $\mathrm{CE}$ for the entire manufacturing process.

In our approach, a $\mathrm{CE}$ increase (hereafter $\Delta \mathrm{CE}$ ) is defined as the average value of the resulting, new efficiency for a catalyst for a specific conversion process, as compared to the best "bench mark" catalysts; the benchmark representing the (current) best-performing heterogeneous catalyst to-date.

Thus:

$\mathrm{CSI} \#=\frac{\Delta \mathrm{gCO}_{2} / \text { MJFuel }}{\Delta \text { Catalyst Efficiency }}$

\# For a given $\Delta$-change in $\mathrm{gCO}_{2} / \mathrm{MJ}_{\text {fuel }}$ or corresponding change in $\mathrm{CE}$.

\subsection{Axiom (Catalyst Efficiency)}

A catalyst is conventionally defined by several important criteria related to its efficiency (e.g. its catalytic activity and selectivity) and its stability (i.e. its catalytic lifetime). The efficiency-the operating catalytic rate-is conveniently given in terms of the Turnover Frequency (for example, moles of product formed per hour) or more commonly in conversion and selectivity The lifetime of the catalyst, before deactivation or unloading, is quantified using time-on-stream or stability, which is the period of the catalyst in the chemical reaction. Normally the life-time of a catalyst is relevant to the reaction conditions and subject to a certain level of conversion and selectivity.
Of course, we note that CE does not always necessarily equal catalyst performance; it is in fact an increase in the catalyst performance that signifies improvement. $\mathrm{CE}$ is given by the following expression:

Catalyst efficiency $(\mathrm{CE})=(\mathrm{Cn} / \mathrm{Co}+\mathrm{Sn} / \mathrm{So}+\mathrm{Ln} / \mathrm{Lo}) / 3$

where $\mathrm{Cn}$ is the conversion of the new or improved catalyst, $\mathrm{Co}$ is the conversion of the benchmark catalyst $(\mathrm{CE}=1.0)$;

$\mathrm{Sn}$ is the new or improved catalyst selectivity, and So is the benchmark catalyst selectivity;

Ln is the life time of the catalyst and Lo is the benchmark catalyst life time

To avoid the necessary extra (longer) lifetime of the catalyst under very low conversion and selectivity conditions, which is in fact true in many operational cases, here we define that $\mathrm{Cn}$ and Sn must be higher than Co and So.

\section{Results and Discussion}

\subsection{The Catalyst Sensitivity Index: A Complete Lifecycle Analysis (LCA) of Algae-to-Biofuel; Coal-to-Liquid and Gas-to-Liquid Fuel Production and Conversion Processes}

The CSI is defined to derive from current or best performance heterogeneous catalysts as the benchmark (origin) and then one evaluates quantitative conclusions as to the resulting total energy and total $\mathrm{CO}_{2}$ footprint gains one could anticipate with a higher efficiency from the operating catalyst.

Through comparing complete LCA's among these different fuel synthesis and conversion processes, the resulting CSI values are derived from the total energy input or $\mathrm{CO}_{2}$ emission (carbon footprint) reduction versus increases in the $\mathrm{CE}$.

This approach will help highlight, and quantify, where the most significant total energy $\left(\mathrm{MJ}_{\text {fuel }}\right)$ and total $\mathrm{CO}_{2}$ $\left(\mathrm{gCO}_{2}\right)$ emissions footprint gains are to be made from enhancements in the efficiency or performance of the catalyst within the entire fuel synthesis or conversion process. Of course, an ideal situation for targeting advances in catalytic science would be those fuel synthesis or conversion processes which emerge as highly catalyst-sensitive; for such processes, small improvements in catalyst efficiencies would yield considerable reductions in the total energy and corresponding total $\mathrm{CO}_{2}$ footprints. This would lead to a high value of the CSI.

The opposite situation would reflect predominantly catalyst-insensitive contributing processes where 
improvements in catalyst efficiencies would not significantly impact upon the overall energy/carbon footprint of the fuel synthesis or conversion process. This would lead to a low value of the CSI.

To illustrate the factors contributing to the CSI and their impact on prototypical fuel production and conversion processes, we investigate the various carbon-containing Feedstock-to-Transport Fuel conversions through the Fischer-Tropsch process, $[6,12,25,37-43]$ where the carboncontaining feedstock is first converted into syngas, a mixture of $\mathrm{H}_{2}$ and $\mathrm{CO}$ and subsequently converted into crude synfuel, and further refined to the desired fuel fraction. The entire process sub-units which comprise the complete Well -to-Tank processes have been defined in Fig. 1.

The contributing processes for the manufacture of what we term "Fischer-Tropsch Fuel" has been specifically studied through a complete LCA, and this process is typically involved as a key aspect of the following fuel production or conversion processes: (1) Algae-to-Biodiesel, (2) Algae-to-Jet Biofuel, (3) Coal-to-Liquid (CTL) and (4) Gas-to-Liquid (GTL); these processes have been subjected to a full LCA for all aspects of the production and conversion processes. The change of the total energy input from the full LCA of the WTT plotted against the CE for these four processes is presented in Fig. 2.

The Algae-to-Biodiesel fuel production technology first proceeds through the algae transesterification process, where $\mathrm{NaOH}$ and $\mathrm{KOH}$ catalysts are employed. We find from our LCA that the most significant energy input and, accordingly, one of the most significant $\mathrm{CO}_{2}$ emission routes (note: assuming fossil-derived input energy sources) originates in the harvesting (collection), drying and subsequent pyrolysis processes. The subsequent process of Jet Biofuel production occurs through hydrogenation of the Bio oil or Biodiesel, so as to remove the ever-present oxygen moieties in the various oxygenate fractions. This process does not require any gasification step, which, importantly, we find to be highly energy intensive. Existing Algae-to-Biodiesel, and beyond to Algae-to-Jet Biofuel production, from transesterification and subsequent hydrogenation are given as benchmark values (setting $\mathrm{CE}=1.0$, with the best industrial catalyst to-date, $\mathrm{KOH} /$ $\mathrm{NaOH}$ ) and are characterized by a resulting low (i.e. primarily catalyst-insensitive) CSI factor.

We now encounter a qualitatively different situation in the CTL and GTL fuel synthesis and conversion processes (Fig. 2); both adopt the 1st stage syngas production and then the 2nd stage Fischer Tropsch synthesis to produce synfuel using, typically, a $\mathrm{Ru} / \mathrm{Co} / \mathrm{Fe}$ catalyst.

Complete sensitivity analyses of our LCA illustrate the highly significant impact of an increased CE or activity on the relative reduction in net (total) Fischer-Tropsch (fossil) fuel energy consumption and $\mathrm{CO}_{2}$ emissions as well as catalyst selectivity of the respective feed load to the FT fuel upgrading stage.

According to the literature, $[6,12,37,41,44,45]$ the (present) best formulation catalyst for lower temperature Fischer Tropsch synthesis catalyst is routinely a ruthenium - promoted cobalt and iron catalyst (here $(\mathrm{Ru} / \mathrm{Co} / \mathrm{Fe})$ in Fig. 2) for the production of Gas-to-Liquid or Coal-toLiquid fuels. In some cases, for chemical and olefins production from syngas, an iron catalyst is also adopted in the
Fig. 2 The derivation of the CSI-factor for four fuel conversion processes. Algae Biodiesel and Algae Jet Biofuel are derived from (1) Algae transesterification and (2) Algae Hydrogenation. For these two processes the LCA reveals a low CSI-factor; being primarily catalyst-insensitive. In contrast, fuels manufactured involving Fischer-Tropsch synthesis routes [i.e. Coal-to- Liquid (3) and Gas-to-Liquid (4)] show a significant, and high sensitivity on Catalyst Efficiency and therefore, par definition, exhibit a high CSI factor. Note, throughout, we assume fossilfuel-derived input energy sources

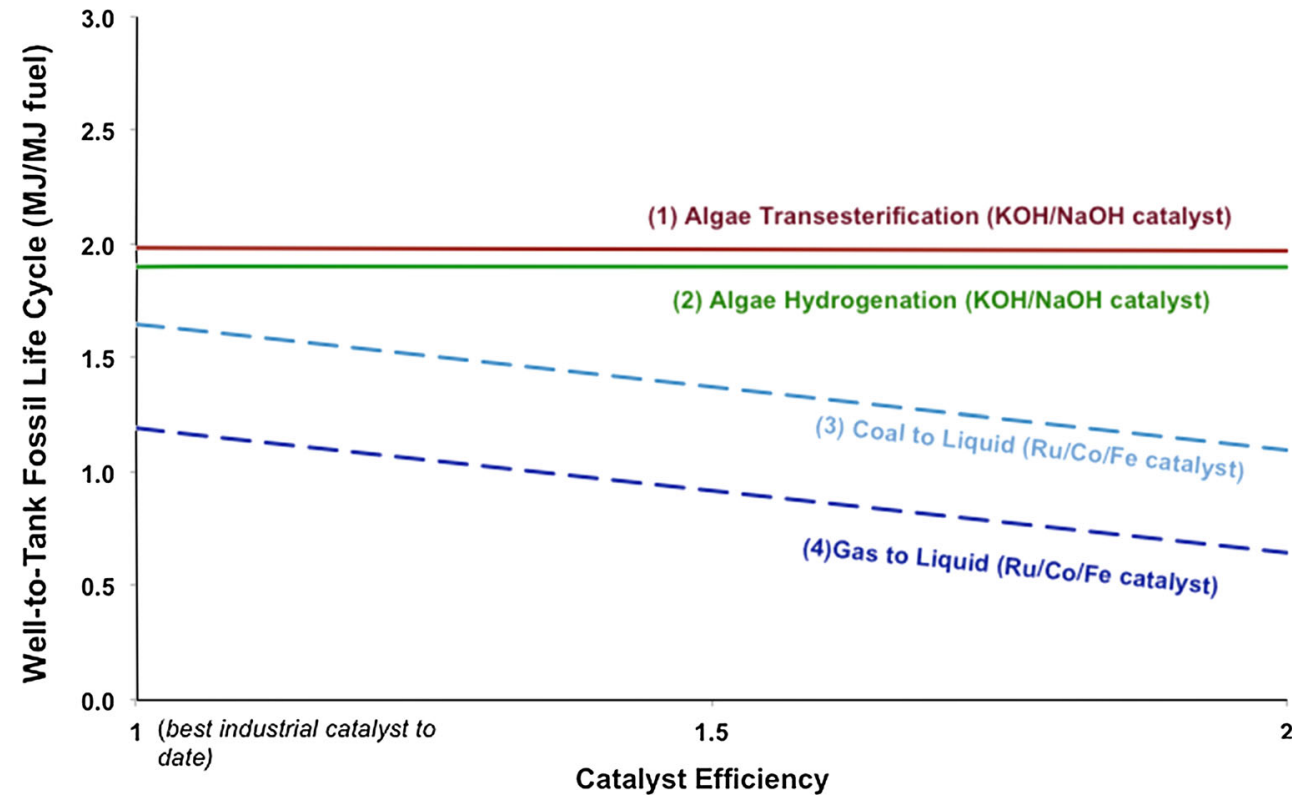


Coal-to-Liquid process, as the $\mathrm{H}_{2} / \mathrm{CO}$ ratio is relatively low, while iron can assist the water gas shift reaction $[6$, $21,40]$.

Here we have focused only on the fuel synthesis or production itself, and the additional iron catalyst is not considered in our evaluations. The synthesized hydrocarbon from any Fischer-Tropsch process is then hydrocracked into the desired fuel fraction. The resulting CE is based on the accumulation of the Fischer-Tropsch synthesis and also the hydrocracking (HCR); typically, over a modified acid zeolite catalyst.

It is important to note that for this study, FischerTropsch fuel production volumes and mass balance are assumed constant, and no further consideration of heat recycling and feedback loops have been explicitly taken into account. This has mainly been assumed, as the allocation of energy consumption and GHG emissions for the separation and upgrading step is driven primarily by recycled heat, which has been generated by earlier gasification and water gas shift steps where heat and syngas are produced to power the whole system.

In all cases, from these LCA studies, it is readily apparent that the energy input, and resulting $\mathrm{CO}_{2}$ emission profiles for the production both of Biodiesel and Jet Biofuel from algae, is clearly not as sensitive to increases in the $\mathrm{CE}$ as that of CTL and GTL processes. Importantly, we note that the entire process for the algae feedstock conversion to both fuels is dominated by the external (input) fossil fuel energy, and associated total $\mathrm{CO}_{2}$ emissions, for the various processing steps noted earlier.

Thus, the calculated energy input for $1 \mathrm{MJ}$ fuel production for the two algae-based processes is $c a$. $2.0 \mathrm{MJ} / \mathrm{MJ}$ fuel and does not change noticeably with any increases in the efficiency of the $\mathrm{KOH} / \mathrm{NaOH}$ catalysts driving both the transesterification and subsequent hydrogenation processes (Fig. 2).

In contrast, for the CTL and GTL processes, the resulting energy input for $1 \mathrm{MJ}$ fuel production decreases almost linear with the CE. The overall gap between the energy inputs of Coal-to-Liquid and Gas-to-Liquid fuel production is consistently about $0.4 \mathrm{MJ} / \mathrm{MJ}$ fuel, the higher energy consumption for Coal-to-Liquid is due to the inherent energy intensive process, e.g., not only gasification, but also gas conditioning.

However, once syngas is synthesized with a desirable $\mathrm{H}_{2} / \mathrm{CO}$ ratio, the energy consumption for fuel generation decreases almost linearly with the CE improvement, and, interestingly, the slope of the CTL and GTL energy/fuel/consumption versus catalyst efficiency is almost the same, demonstrating that the CSI in the two processes is comparable. This important outcome can be understood by the fact that these two different processes, nevertheless, both go through the Fischer Tropsch synthesis step and HCR, which is indeed identical in both cases, in terms of the necessary fossil fuel energy requirements and resulting $\mathrm{CO}_{2}$ emissions.

In the simplest-and hopefully most transparent-form of sensitivity analysis applied to the CSI, we have taken to increasing the CE for each particular process by the same amount-taken here as a doubling of the catalyst efficiency - and examined the resulting impact on the total energy and total $\mathrm{CO}_{2}$ footprint for the entire fuel synthesis and conversion processes. To illustrate, we look at those four processes for which we have carried out a complete LCA; namely, Algae-to-Biodiesel, Algae-to-Jet Biofuel, CTL and finally GTL.

One can then cast the CSI formally, in its simplest form as:

$\mathrm{CSI}=\frac{(\mathrm{W}-\mathrm{TE} @ 1.0)-(\mathrm{W}-\mathrm{TE} @ 2.0)}{(\mathrm{W}-\mathrm{TE} @ 1.0)}$

where (W - TE@1.0) is the WTT total energy and total $\mathrm{CO}_{2}$ emissions for the current, most efficient catalyst (having $\mathrm{CE}=1.0$ ) and (W-TE@2.0) is the corresponding WTT energy and $\mathrm{CO}_{2}$ emissions having a $\mathrm{CE}=2.0$ ), (i.e. a doubling of the efficiency of the current best operating catalyst). In terms of the total \% reduction of energy usage and $\mathrm{CO}_{2}$ emissions for the processes driven by a doubling of CE, one then sets CSI* $=(\mathrm{CSI} \times 100) \%$.

As one can see in the Table below, both the Algae Transesterification and Algae Hydrogenation processes have CSI* values very close to zero, while the Coal-toLiquid and Gas-to-Liquid have significantly higher CSI* values of $c a .34$ and $46 \%$ :

\begin{tabular}{ll}
\hline Algae transesterification & $0.0051 \%$ \\
Algae hydrogenation & $0.00001 \%$ \\
Coal-to-liquid & $33.93 \%$ \\
Gas-to-liquid & $46.22 \%$ \\
\hline
\end{tabular}

In terms of the effects of enhancements in $\mathrm{CE}$, a doubling of that efficiency in the CTL and GTL processes will have a highly significant impact on total energy consumption and $\mathrm{CO}_{2}$ emissions for these two processes amounting to a reduction of almost $50 \%$. It is reassuring that both the CTL and GTL processes have rather similar CSI values, reflecting the critical, underlying importance of the catalytic Fischer-Tropsch process in both cases.

In stark contrast, both the algae transesterification and algae hydrogenation processes would yield almost zero, and indeed zero, respectively, changes in the overall total energy and total $\mathrm{CO}_{2}$ emissions from a doubling of the $\mathrm{CE}$ with the dominant contributions to both processes derived from the fossil-fuel derived processes of drying, etc. 
A further detailed breakdown of the complete WTT Lifecycle Energy Demand profile for the production of CTL and GTL Fuel conversion processes is given in Fig. 3. It outlines the relative contribution of the Fischer-Tropsch fuel production stages and highlights the underlying (fossil fuel) energy demand of the Fischer-Tropsch reactor as the second largest energy consumer after the Fischer-Tropsch gasification and syngas clean-up stage.

The potential reduction in the Fischer-Tropsch reactor's net energy consumption, through increased CE, as well as improvements to the consequent feed load of the FT-fuel upgrading stage, through for example, higher catalyst selectivity and longer life-time, are vividly illustrated in this analysis (Fig. 3). However, as part of the fuel upgrading and refining step, the contribution from zeolite catalysts to the overall energy and emissions balance remain relatively small.

\subsection{The Catalyst Sensitivity Index: A Comparison of Fluid Catalytic Cracking (FCC), Hydrocracking (HCR) and Hydrogen Generation through Steam Methane Reforming (SMR) Processes}

Nowadays with the ongoing depletion of conventional light oil reserves and an ever-increasing supply of heavy oil distillates, fluidized catalytic cracking (FCC) has become one of the most important hydrocarbon fuel conversion processes used in petroleum refineries [46-48]. It is widely used to convert the high-boiling, high-molecular weight hydrocarbon fractions of heavy crude oil to more valuable (lighter product) gasoline and diesel fractions, and other important products.

The vast majority of modern oil refineries use this incumbent technology to correct the imbalance between the

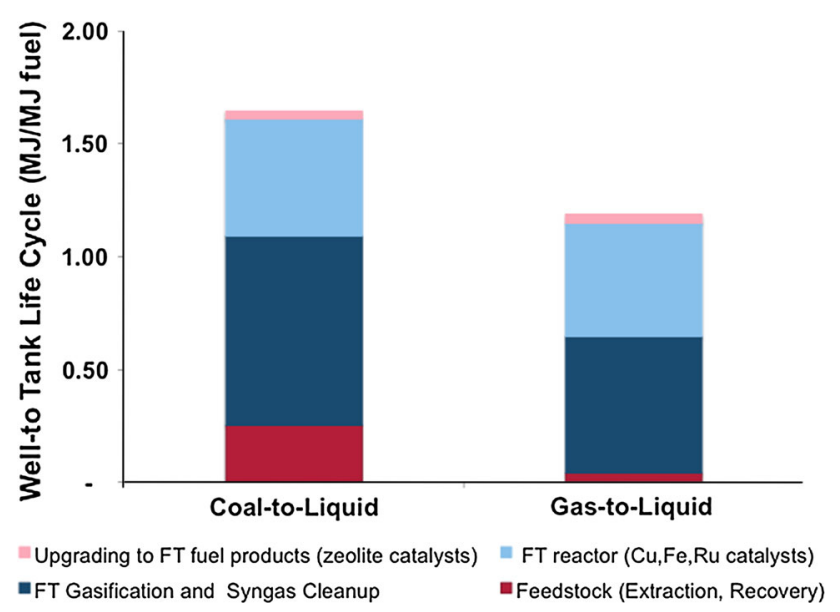

Fig. 3 Well-to-tank life cycle energy demand for the production of CTL and GTL fuels; we identify here the component processes and their respective energy demands global market demand for gasoline and diesel fuels and the excess supply of heavy, high-boiling range products resulting from the distillation of crude oil [30, 46, 49-52]. However, the ever-present generation of significant carbon deposits over the FCC catalyst, which requires continuous monitoring and regeneration of the catalyst, routinely through aerial combustion of the deactivated catalyst particles, represents a major problem. In addition, during any regeneration process, considerable amounts of $\mathrm{CO}_{2}, \mathrm{SO}_{2}$ and NOx, and even carbon and other particulates are produced from the carbon and nitrogen deposits over the catalyst. On the other hand, the sulfur and nitrogen, and even some metal constituents, in the resulting oil fractions require further significant upgrading, either through hydrotreatment or Hydrocracking (HCR) or further vacuum/thermal distillation processes.

Notwithstanding these problems, the FCC process efficiency with modern catalysts is generally about 96-98\% [30]; however, this invariably does not take into consideration the emerging and deleterious carbon deposit over the catalyst, which is often between $0.5-7 \mathrm{wt} \%$ in the spent catalyst. The FCC catalyst has become the biggest oil processing unit, with the catalyst usage for residue, VGO and hydrotreating feeds estimated at $0.4,0.17$ and $0.14 \mathrm{lb} /$ $\mathrm{bbl}$, respectively, resulting in a worldwide demand for heavy cracking catalysts of about 1960 metric tons per day, depending on the specifications of the particular crude oil properties, especially the conradson carbon content $[47,49$, 50].

To avoid significant carbon deposition and present more desirable products from the feed, the process of hydrocracking (HCR) is now becoming an attractive alternative to FCC as the modern refinery conversion process choice [5358]. This also stems from the fact that "dieselization" is rapidly developing in many parts of the world, and HCR processing makes it relatively easy to manipulate the socalled product slate to meet rapidly changing market demands. This process also enables the ready manufacture of high-quality transport fuels, particularly ultra-low-sulphurcontent diesel, directly from difficult-to-process input feeds.

Finally, the HCR process can be significantly improved with an increase in the hydrogen partial pressure, but, one notes of course, at the expense of significant hydrogen consumption in this process, with the attendant, underlying large carbon footprint (since hydrogen is derived industrially from the Steam Methane Reforming) [53, 54, 58-60]. The performance of hydrocracking units is fundamentally and critically dependent on the zeolite catalyst used to break down the heavier oil molecules, and hydrotreatment catalysts, which are in fact designed for the combination of the cracking and hydrotreatment dual functions.

Another important catalytic chemical process, which is in fact also a key technology to hydrogen economy, is the 


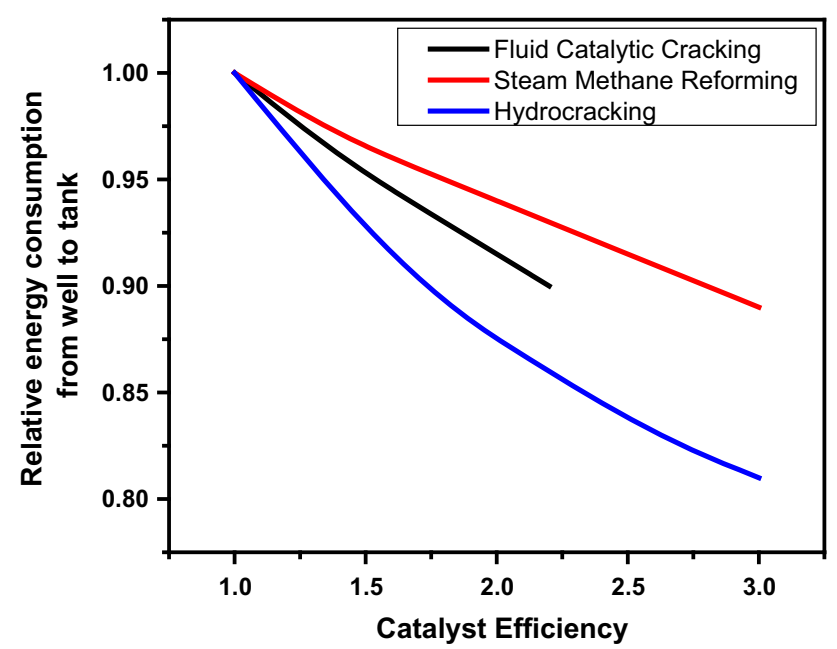

Fig. 4 The anticipated changes of the relative energy consumption with the defined catalyst efficiency among the processes of fluid catalytic Cracking (FCC), $\mathrm{H}_{2}$ production from steam methane reforming (SMR) and hydrocracking (HCR)

process of the steam methane reforming (SMR). There, a highly active catalyst is essential; however, the mass and heat transfer of the process itself are highly significant components of the resulting energy balance and resulting $\mathrm{CO}_{2}$ emissions [15, 37, 59, 61-64]. Notwithstanding these major issues, SMR has been extensively used in the chemical and energy industries for several decades now, even though the responsible catalyst active site is routinely less than $10 \%$. Considerable efforts, worldwide, have attempted to improve the overall efficiency of the process $[60,64]$, driven both by the economic and environmental desire to decrease the total energy consumption (carbon footprint) for the resulting fuel (hydrogen) production.

We have attempted to confront the challenge of beginning to determine the CSI for such complex-but highly important-modern fuel production and conversion processes. Taking, once again, the currently highest performing catalyst as the benchmark (with CE taken as 1.0), the resulting semi-quantitative estimates of the change of relative energy consumption for fuel production from Wheelto-Tank with the corresponding CE is shown in Fig. 4. We note that, as compared to our previous complete LCA for the other four fuel production and conversion processes, this is presently our attempt at a semi-quantitative assessment arising from a literature review and analysis of the contributing catalytic practices and performances. All three processes shown here will clearly benefit from a full LCA approach as highlighted earlier, but the present approach hopefully illustrates how these fuel production/ conversion processes can be subjected to this new type of analysis.

From Fig. 4, it is clear that the resulting slope of energy consumption versus $\mathrm{CE}$ characterizing the hydrocracking process is considerably more than that of the FCC process.
Thus, for a doubling of the CE, the relative energy consumption can be expected to decrease to a value close to 0.88 of that of the existing "Best-in-practice" catalyst (set at $\mathrm{CE}=1.0$ ). Such an advance would obviously be realized from an increase in catalyst activity thus requiring less external (fossil fuel) energy input, together with an enhancement of catalyst selectivity to more desirable (target) products, which can decrease the catalytic cycles and therefore consume less hydrogen in both the production and conversion processes. The extension of the catalyst life-time can obviously also lead to less waste generation and enhanced product yields.

For the HCR process, it has been shown that the carbon content on spent hydrodesulphurization catalysts largely varies: from 5 to $25 \mathrm{wt} \%$, with an average for diesel units at 10-15 wt $\%$. Units processing atmospheric gas oils or vacuum gas oils typically run from 1 to 2 years. Each year, more than $10 \mathrm{k}$ tons of hydrotreatment and HCR catalysts are used worldwide. The major factor for the catalyst deactivation results from carbon deposition, which is again burnt-off during the regeneration or waste catalyst recovery. Also the sulfide active phase of any HCR catalyst would lead to enhanced sulfur dioxide emissions, which again necessitates extra energy input in the recovery of the metal or, indeed, to enhance its activity. Thus, it is seen that should the catalyst life-time be doubled, leading to an increase in the catalyst performance metric, this will be expected to yield significantly less energy input and correspondingly lower $\mathrm{CO}_{2}$ emissions. In addition, the active site of the catalyst could be tailored to be more resistant to coke formation. This type of analysis, therefore, highlights that the HCR process has considerably higher potential for CE development.

Turning now to the FCC process; here the CE can also have significant effect on the relative energy consumption (Fig. 4). This can be understood by the (known) fact that after even a few cycles, the induced coke on the active catalyst needs to be burnt-off to regenerate the operating catalyst. In addition, higher CE (activity) would enable the cracking process to occur at lower temperature, which clearly requires less energy input, producing less $\mathrm{CO}_{2}$ and would also enhance the process efficiency. The increase of the catalyst life-time and the selectivity will also help the energy consumption for the complete fuel production process.

As noted previously, the total amount of catalyst consumed worldwide each year is in the region of 60,000 tons, and the carbon deposition content of up to $5 \mathrm{wt} \%$ due mainly to an increasingly heavy oil supply [65, 66]. In fact, if these carbon depositions can be depressed through the tailoring of the catalyst acid site and the formulation, more products could be obtained and significantly less emission would result. 
In relation to hydrogen fuel production from SMR, the change in the relative energy consumption against $\mathrm{CE}$ is not as significant as either that of the FCC or the HCR process. This simply arises because the catalysts for SMR are known to have considerably more active sites available; however, in this process, it is known that the heat and mass transfer over the catalyst is significantly more important than any intrinsic physicochemical properties of the catalyst itself. In fact, in recent developments, considerably more attention has been paid to the physical properties improvement of the catalyst bed, etc., rather than the catalyst formulation, as the mass and heat transfers are the true determining steps-and energy-consuming steps-in the entire process.

For SMR, as shown in many studies, the intrinsic catalyst activity is rarely a limiting factor. The catalyst volume (space velocity) is fixed from the tubular reformer design. The equilibrium conversion at high reforming temperatures is achieved at even very high space velocities when extrapolating the intrinsic rates. In practice, however, the utilization of the catalyst activity (as expressed in the literature through the so-called "effectiveness factor") is smaller than $10 \%$ because of reactant/product transport restrictions. It can be shown by computer simulations that the catalyst performance by itself is not the limiting factor for the design of a tubular reformer. An increase of the heat flux and the load at a given exit temperature by a factor of two results in an increase in methane leakage by only $10 \%$ [63].

SMR catalysts (e.g. traditional tubular nickel catalysts) have a typical lifetime of 3-5 years, when employed for large-scale hydrogen production (1,000,000 scf/day). Primary steam reforming catalysts contain 10-20\% Ni supported on $\alpha-\mathrm{Al}_{2} \mathrm{O}_{3}$, calcium aluminate, or magnesium aluminate. Typically, natural gas steam reformers are operated with exit temperatures from 800 to $870{ }^{\circ} \mathrm{C}$. However, importantly for this present analysis, the catalyst life-time (hence efficiency) can still be improved from the process and feedstock quality control, as the carbon deposition can be reduced or significantly avoided through careful control of the steam/carbon ratio. In fact, the catalyst deactivation mainly results from sufur poisoning in most cases [67-69].

From Fig. 4, we show that the HCR process has a higher CSI than the FCC process, whose CSI is itself higher than the SMR for hydrogen production. Therefore, from this CSI analysis, in order to attain a significant total $\mathrm{CO}_{2}$ emission reduction in these three modern fuel production processes, we would propose that considerably more attention should be focused on the development and improvement of both HCR and FCC catalysts for enhanced efficiencies and performance.

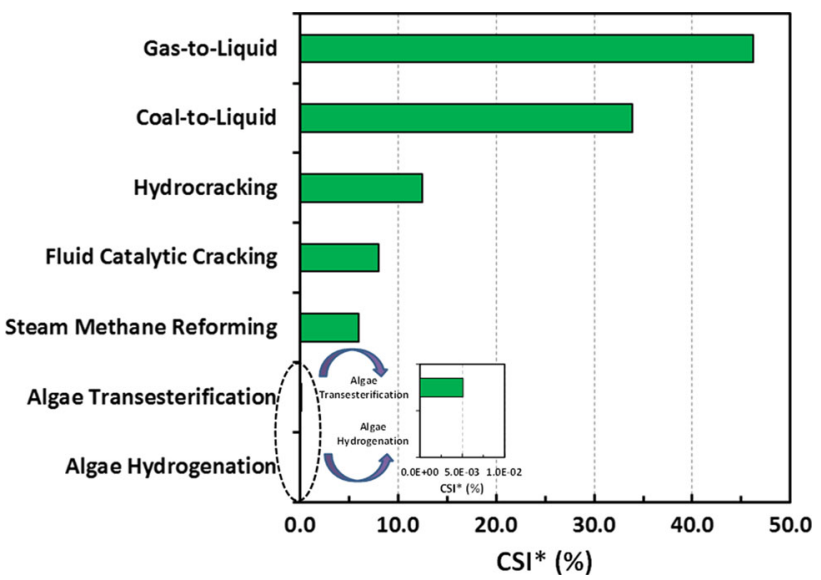

Fig. 5 The Catalyst Selectivity Index [expressed as CSI* (\%)] for various catalytic processes involving fuel production and conversion

In Fig. 5 we show the resulting CSI* values for these various catalytic processes. Note that the derived values for the SMR, FCC and HCR processes are derived for our semi-quantitative LCA, while the other processes are derived from a complete Well-to-Tank LCA.

From Fig. 5, one can clearly see that the CSI is strongly dependent upon the particular catalytic process. For instance, the very low CSI* values for the algae transesterification and algae hydrogenation reactions arise as a consequence of the extremely weak dependence of the total energy consumption and total $\mathrm{CO}_{2}$ emissions on the $\mathrm{CE}$ and performance. In contrast, the total energy consumption and total $\mathrm{CO}_{2}$ emissions are strongly affected by enhancements in the CE when we consider the CTL, GTL and even the HCR processes. It is worth highlighting that the underpinning endo- or exo-thermicity of any particular catalytic reaction may play a major role in this trend [70]. Indeed, the higher endothermicity of hydrogen production from SMR compared to HCR and FCC reactions, which is reflected in its higher reaction temperatures (i.e. 700-1000 ${ }^{\circ} \mathrm{C}$ for SMR) than those for HCR and FCC reactions (i.e. $350-550{ }^{\circ} \mathrm{C}$ ), could also rationalize its higher relative energy consumption and resulting $\mathrm{CO}_{2}$ emissions into the whole range of $\mathrm{CE}$ assessed in this work (Fig. 4). All such factors will need to be quantitatively accounted for in any other catalytic processes to which the CSI concept can be applied in the future; certain other important processes that we believe would benefit from this sort of approach are noted below.

We find that improvements in CE have a most significant impact on the CTL and GTL processes through the production of syngas, then to Fischer-Tropsch fuels via this route. The improvement of a Fischer-Tropsch catalyst can significantly reduce the total energy consumption for the CTL and GTL and also algae- (gasification) to-liquid 
fuel through the component Fischer-Tropsch synthesis. In contrast, the algae-to-biodiesel or algae-to-biojet fuel through the esterification process cannot be improved greatly through any significant catalyst improvement. These findings arise from a complete LCA of the total fuel production and conversion processes.

The other three leading energy production and conversion processes, e.g. FCC, hydrogen production from SMR and HCR, have been analyzed using a semi-quantitative LCA with the CSI methodology. We find that the greatest total energy and total $\mathrm{CO}_{2}$ emissions saving can be realized through a $\mathrm{CE}$ improvement for the HCR process, followed by the FCC process. Any CE improvement has the least effect on the energy and $\mathrm{CO}_{2}$ emission saving for the hydrogen production from the SMR, as the process is generally determined by the heat and mass transfer of the industrial engineering of the catalytic process.

This new CSI concept should, in future, go hand-in-hand with considerations of the Environmental E Factor to help inform decision makers in issues of sustainable practices and environmental efficiency gains expected from advances in catalysis science and technology in the energy production and conversion industries. We realise, of course, that the CSI concept presented here is in a preliminary format, but we believe that it should justify further expansion and development. Thus, it would benefit especially from additional work in the form of Aspen Plus simulations to give more precise results, but also if it could be integrated with other aspects where one assesses the sensitivity of several variables simultaneously.

Indeed, many more catalytic industrial processes, such as methanol from coal, natural gas and biomass; ammonia synthesis from coal and natural gas; olefins production from methanol or naphtha, and ethylene glycol from syngas or ethylene, etc., would also benefit from application of the CSI method and approach so as to highlight those processes for which a (quantifiable) enhancement in CE would assist in the managed transition to sustainable, more environmentally benign, fuel and chemical industries.

It is readily accepted that the formidable challenges of future energy usage and climate change mitigation will require the coalescence of many competences outside of the immediate fields of chemical catalytic science and technology. Equally, the subject of catalysis has the greatest to gain by forming new alliances with other fields-in our view, particularly in the social sciences-to understand, and with that understanding to control, the unquestionable impact of advances in shaping future sustainable energy processes. Thinking about the total energy usage and total $\mathrm{CO}_{2}$ emissions associated with advances in catalyst efficiencies from such an LCA perspective is extremely important if major decisions are to be made about how catalytic science and technology will impact upon climate change mitigation through reductions in energy usage and GHG emissions.

\section{Conclusions}

Catalysts continue to have an enormous, beneficial impact on the chemical, energy, manufacturing and environmental industries. Often the performances of catalysts are characterized by their activity, selectivity and life-time (or stability). However, the precise association-and with that the quantification - of a catalyst performance with any specific environmental benefit of such performance enhancement, such as total energy consumption and $\mathrm{CO}_{2}$ emission footprint, has not previously been correlated. Therefore, it was not always clear which catalytic process to target in making the most significant environmental improvement in developing and applying a heterogeneous catalyst to reduce total energy usage and concomitant $\mathrm{CO}_{2}$ emissions.

We have advanced and developed here a new concept, the CSI, which allows a route to correlate the industrial process energy input and $\mathrm{CO}_{2}$ emission saving with a measurable improvement in $\mathrm{CE}$. We have developed this concept in combination with a complete LCA methodology to analyse the following fuel production and conversion processes, biomass-to-liquid, algae-to-liquid, GTL and CTL, as well as a semi-quantitative assessment of the FCC, HCR and SMR processes.

We hope to have illustrated here that this union of complementary strengths benefit both of the individual streams that will be needed to closely interact in any initiatives to shape the future sustainable fuel and chemical manufacturing technologies. We believe that it will be thrilling for new generations of scientists and engineerscoupled in strong directed alliances with colleagues in the social sciences-to rationally design, and in some cases (hopefully) reinvent yet-higher efficiency catalysts for particular processes specifically targeted as strong contenders to reduce total energy consumption and total $\mathrm{CO}_{2}$ emissions in the generation and conversion of fuels.

One can finally pose the question, "If catalyst efficiency in a particular fuel production or conversion process were to increase from its current ("best") value, by how much would that increase have to be in order for Greenhouse Gas Emissions to be significantly reduced, to a value highly beneficial from a climate change perspective?" This establishes the challenge-and of course the realizationthat the science and technology of catalysis can now quantifiably impact upon and help mitigate climate change. We hope that this contribution highlights the importance of thinking about emission reductions associated with advances in catalysis science from a lifecycle perspective of the social sciences. 
Acknowledgments We thank the Oxford University Smith School for Enterprise and the Environment, and the King Abdulaziz City for Science and Technology and the EPSRC for the generous funding and continual support of this multidisciplinary research. We thank Professor George Whitesides for stimulating discussions on the future directions of chemistry and catalysis science. We also thank Mrs Linda Webb for her considerable, professional help in assembling and typing of this manuscript.

Open Access This article is distributed under the terms of the Creative Commons Attribution 4.0 International License (http://creativecommons.org/licenses/by/4.0/), which permits unrestricted use, distribution, and reproduction in any medium, provided you give appropriate credit to the original author(s) and the source, provide a link to the Creative Commons license, and indicate if changes were made.

\section{References}

1. Thomas JM, Thomas WJ (2015) Principles and practice of heterogeneous catalysis, 2nd edn. Wiley, Hoboken, p 768

2. Freund H-J, Somarjai GA (2015) The frontiers of catalysis science and future challenges. Catal Lett 145:1-481

3. Heveling $\mathbf{J}$ (2012) Heterogeneous catalytic chemistry by example of industrial applications. J Chem Educ 89:1530-1536

4. Speight JC (2011) The Refinery of the future. Elsevier, Amsterdam, p 395

5. Kieboom APG et al (1999) Catalytic processes in industry. In: Catalysis: an integrated approach, 2nd edn. pp. 29-80

6. Krylova AY (2012) Fischer-Tropsch synthesis catalysts as the core of the strategy for obtaining synthetic liquid fuels. Kinet Catal 53(6):742-746

7. Descorme C et al (2012) Heterogeneous catalysis: a key tool toward sustainability. ChemCatChem 4(12):1897-1906

8. Vivanco DF et al (2014) Using LCA-based decomposition analysis to study the multidimensional contribution of technological innovation to environmental pressures. J Ind Ecol 18(3):380-392

9. Cusumano JA (1995) Environmentally Sustainable Growth in the 21st Century. J Chem Educ 72(11):959-964

10. Thomas JM (2014) Heterogeneous catalysts and the challenges of powering the planet, securing chemicals for civilised life, and clean efficient utilization of renewable feedstocks. ChemSusChem 7:1801-1832

11. Liu D, Chen EY-X (2014) Organocatalysis in biorefining for biomass conversion and upgrading. Green Chem 16:964-981

12. de Klerk A (2008) Fischer-Tropsch refining: technology selection to match molecules. Green Chem 10(12):1249-1279

13. Dunn PJ The importance of green chemistry in process research and development. RSC Drug Discovery Ser., 2011. 9(Pharmaceutical Process Development): pp 117-137

14. Sheldon RA (2012) Fundamentals of green chemistry: efficiency in reaction design. Chem Soc Rev 41(4):1437-1451

15. Wilhelm DJ et al (2001) Syngas production for gas-to-liquids applications: technologies, issues and outlook. Fuel Process Technol 71(1-3):139-148

16. Whitesides GM (2015) Reinventing chemistry. Angew Chem Int Ed 54:3196-3209

17. Sheldon RA (2007) Green chemistry: catalysis and waste minimization. In: Tundo P, Perosa A, Zecchini F (eds) Methods and reagents for green chemistry: an introduction. John Wiley \& Sons, Inc., Hoboken, NJ

18. Sheldon RA (2007) The E Factor: fifteen years on. Green Chem 9(12):1273-1283

19. Sheldon RA (2008) E factors, green chemistry and catalysis: an odyssey. Chem Commun 29:3352-3365
20. Sheldon RA (2008) Green and sustainable chemistry: challenges and perspectives. Green Chem 10(4):359-360

21. Verslycke $\mathrm{T}$ et al (2014) The chemistry scoring index (CSI): a hazard-based scoring and ranking tool for chemicals and products used in the oil and gas industry. Sustainability 6(7):3993-4009 17

22. Sheldon RA, Sanders JPM, Marinas A (2015) Sustainability metrics of chemicals from renewable biomass. Catal Today 239:1-2

23. Sheldon RA (2000) Atom efficiency and catalysis in organic synthesis. Pure Appl Chem 72(7):1233-1246

24. Sheldon RA (1999) E factors, atom efficiency, and catalysis in organic synthesis. American Chemical Society, Washington, DC

25. Lutz B (2001) New age gas-to-liquids processing. Hydrocarb Eng 6(11):23-26

26. Iandoli CL, Kjelstrup S (2007) Exergy analysis of a GTL process based on low-temperature slurry F-T reactor technology with a cobalt catalyst. Energy Fuels 21(4):2317-2324

27. Shirvani T (2012) The environmental feasibility of algae Biodiesel production. Appl Petrochem Res 2(3-4):93-95

28. Xie X, Wang M, Han J (2011) Assessment of fuel-cycle energy use and greenhouse gas emissions for Fischer-Tropsch diesel from coal and cellulosic biomass. Environ Sci Technol 45(7):3047-3053

29. Hao $\mathrm{H}$ et al (2010) Energy consumption and GHG emissions of GTL fuel by LCA: Results from eight demonstration transit buses in Beijing. Appl Energy 87(10):3212-3217

30. Forman GS et al (2014) U.S. Refinery efficiency: impacts analysis and implications for fuel carbon policy implementation. Environ Sci Technol 48(13):7625-7633

31. ISO 14040 International Standard (2006) In; environmental management -life cycle assessment-principles and framework. International Organisation for Standardization, Geneva

32. Cooney G, Hawkins TR, Marriott J (2013) life cycle assessment of diesel and electric public transportation buses. J Ind Ecol 17(5):689-699

33. Intini F, Kuehtz S (2011) Recycling in buildings: an LCA case study of a thermal insulation panel made of polyester fiber, recycled from post-consumer PET bottles. Int J Life Cycle Assess 16(4):306-315

34. Shirvani $\mathrm{T}$ et al (2011) Life cycle energy and greenhouse gas analysis for algae-derived bio-diesel. Energy Environ Sci 4(10):3773-3778

35. Forman GS, Hahn TE, Jensen SD (2011) Greenhouse gas emission evaluation of the GTL pathway. Environ Sci Technol 45(20):9084-9092

36. Bjoerklund AE (2002) Survey of approaches to improve reliability in LCA. Int LCA Methodol J 7(2):64-72

37. Aasberg-Petersen $\mathrm{K}$ et al (2011) Natural gas to synthesis gascatalysts and catalytic processes. J Nat Gas Sci Eng 3(2):423-459

38. Bakkerud PK (2005) Update on synthesis gas production for GTL. Catal Today 106(1-4):30-33

39. Bao B, El-Halwagi MM, Elbashir NO (2010) Simulation, integration, and economic analysis of gas-to-liquid processes. Fuel Process Technol 91(7):703-713

40. Grobler M (2008) Top technologies. Hydrocarbon Eng 13(6): 93 , 95-97

41. Vosloo AC (2001) Fischer-Tropsch: a futuristic view. Fuel Process Technol 71(1-3):149-155

42. Yagi $F$ et al (2004) Development of synthesis gas production catalyst and process. Prepr Symp 49(2):652-653

43. Zhang $\mathrm{C}$ et al (2014) Efficient utilization of greenhouse gases in a gas-to-liquids process combined with $\mathrm{CO}_{2}$ /steam-mixed reforming and Fe-based Fischer-Tropsch synthesis. Environ Sci Technol 48(14):8251-8257

44. Sousa-Aguiar EF, Noronha FB, Faro A Jr (2011) The main catalytic challenges in GTL (gas-to-liquids) processes. Catal Sci Technol 1(5):22-37 
45. Wood DA, Nwaoha C, Towler BF (2012) Gas-to-liquids (GTL): a review of an industry offering several routes for monetizing natural gas. J Nat Gas Sci Eng 9:196-208

46. Al-Mayyahi MA, Hoadley AFA, Rangaiah GP (2013) $\mathrm{CO}_{2}$ emissions targeting for petroleum refinery optimization. Wiley, New York

47. Parthasarathi RS, Alabduljabbar SS (2014) HS-FCC high-severity fluidized catalytic cracking: a newcomer to the FCC family. Appl Petrochem Res 4(4):441-444

48. Zhang $Z$ et al (2014) The development of FCC catalysts for producing FCC gasoline with high octane numbers. Appl Petrochem Res 4(4):379-383

49. Habib ET, Jr, et al (2002) Advances in fluid catalytic cracking. Catal Sci Ser 3(Zeolites for Cleaner Technologies): pp 105-130

50. Letzsch W, Santner C, Tragesser S (2010) Improving the profitability of the FCCU. Chem Ind (Boca Raton, FL, USA) 129(Advances in Fluid Catalytic Cracking):91-100

51. Maholland MK (2005) The future of FCC catalysts. Hydrocarbon Eng 10(9):23-24, 26

52. Nee JRD, Sobrinos S, Tombolesi B (2001) Recent advances in FCC catalyst and additive technologies to meet new refinery challenges. Pet Coal 43(3-4):132-138

53. Al Musa FF et al (2012) GHG emissions reduction via energy efficiency optimization, greenhouse gases-emission, measurement and management. In: Liu G (ed) InTech. http://www.intechopen. com/books/greenhouse-gases-emission-measurement-and-manage ment/ghgemissions-reduction-via-energy-efficiency-optimization

54. Mohanty S, Kunzru D, Saraf DN (1990) Hydrocracking: a review. Fuel 69(12):1467-147352

55. Castaneda LC, Munoz JAD, Ancheyta J (2012) Combined process schemes for upgrading of heavy petroleum. Fuel 100: $110-127$

56. Dahlberg AJ et al (2005) New generation catalysts. Hydrocarb Eng 10(9):27-30

57. Olsen T (2014) An oil refinery walk-through. Chem Eng Prog 110(5):34-40

58. Weitkamp J (2012) Catalytic Hydrocracking-Mechanisms and Versatility of the Process. ChemCatChem 4(3):292-306
59. Gehrke $\mathrm{H}$ et al (2010) Hydrogen: a small molecule with large impact. In: The future role of hydrogen in petrochemistry and energy supply, DGMK conference, October 4-6, Berlin, Germany

60. Valavarasu G, Bhaskar M, Balaraman KS (2003) Mild hydrocracking: a review of the process, catalysts, reactions, kinetics, and advantages. Pet Sci Technol 21(7 \& 8):1185-1205

61. Cobden PD et al (2007) Sorption-enhanced hydrogen production for pre-combustion $\mathrm{CO} 2$ capture: thermodynamic analysis and experimental results. Int J Greenhouse Gas Control 1(2):170-179

62. Kumar A et al (2014) Smart manufacturing approach for efficient operation of industrial steam-methane reformers. Ind Eng Chem Res 54(16):4360-437060

63. Lee J-Y et al (2011) Eco-efficiency of $\mathrm{H}_{2}$ and fuel cell buses. Int J Hydrogen Energy 36(2):1754-1765

64. Rawadieh S, Gomes VG (2009) Steam reforming for hydrogen generation with in situ adsorptive separation. Int J Hydrog Energy 34(1):343-355

65. Letzsch WS, Mauleon J-L (2002) Changes in catalytic cracking. Hydrocarbon Eng. 7(7):85-88

66. Letzsch WS, Ross JL, Minton P (1998) Fluid catalytic cracking revamps to maintain a competitive edge. Int $\mathbf{J}$ Hydrocarb Eng $3(2): 26-30,32$

67. Deshmukh SR et al (2010) Scale-up of microchannel reactors for Fischer-Tropsch synthesis. Ind Eng Chem Res 49(21): 10883-10888

68. Chen Y et al (2013) Numerical study of hydrogen production via sorption-enhanced steam methane reforming in a fluidized bed reactor at relatively low temperature. Chem Eng Sci 92:67-80

69. Adris AM, Elnashaie SSEH, Hughes R (1991) A fluidized bed membrane reactor for the steam reforming of methane. Can $\mathrm{J}$ Chem Eng 69(5):1061-1070

70. Van Vliet OPR, Faaij APC, Turkenburg WC (2009) FischerTropsch diesel production in a well-to-wheel perspective: a carbon, energy flow and cost analysis. Energy Convers Manag 50:855-876 